\title{
Deakin University: Going Online At A Dual Mode University
}

\author{
Jocelyn Calvert
}

\begin{abstract}
Deakin is a dual mode university with more than half of its students doing at least part of their study at a distance and with an entrepreneurial arm that provides distance education services for even larger numbers. Online provision has been developing over a decade, enriching traditional distance education in programs with mixtures of on- and off-campus students. It has been supported by central services and corporate applications, leading to reasonable consistency in the thrust. A current aim is to ensure that it is sustainable at a high level of quality.
\end{abstract}

\section{Introduction}

Deakin University is situated in the state of Victoria in Australia. It is a moderately large university of 28,192 students (18,171 equivalent full-time student load). It is also a dual mode university, with $43 \%$ of its students studying off campus ( $24 \%$ equivalent full-time student load) and a further $12 \%$ studying in mixed mode ( $18 \%$ equivalent full-time student load). Twenty two percent of Deakin students are from other countries, but only about a quarter of these are off-campus students studying in other countries (with the largest number in Malaysia). There are almost equal proportions of men and women studying off-campus and their average age is 34 years. Over $40 \%$ reside in communities where Deakin has campuses, $56 \%$ live in the state of Victoria, $36 \%$ in other parts of Australia and $8 \%$ overseas.

Almost half of off-campus students are in undergraduate degree programs; $34 \%$ are in postgraduate programs and $17 \%$ are in pre-degree certificates and diplomas. All five faculties have off-campus programs but two-thirds of students are enrolled in two faculties, Arts, and Business and Law.

Deakin has six campuses as the result of mergers in the early 1990s of the original Geelong-based university with colleges in Melbourne and Warrnambool. Negotiating the distance between the campuses is an important challenge of university operations, as the driving time between the easternmost campus in Melbourne and the westernmost campus in Warrnambool is approximately 5 hours. 
In spite of these distances, Deakin is not a federated university. Its five faculties (Arts; Business and Law; Education; Health and Behavioural Sciences; and Science and Technology) operate on multiple campuses, offering the same programs in different locations and off campus. Similarly, the administrative and academic support divisions of the university are integrated and provide their services in multiple locations. Furthermore, and unlike most Australian universities with distance education programs, Deakin has always served off-campus and on-campus students through the same administrative and support infrastructure; there has never been a separate unit responsible for the broad range of off-campus services.

The University has a private division, Deakin Australia, which is a major commercial provider of educational programs. It is one of the largest suppliers of training in Australia, working with more than 50 organisations and its client list includes some of Australia's largest companies, professional associations, unions and government bodies. It provides educational services for approximately 34,500 distance education students, primarily in Australia as well as Europe and Asia, with offices in Geelong, Melbourne, Sydney, Canberra and Washington DC. While many of the programs offered through Deakin Australia are of the continuing education variety, some articulate into Deakin degrees; others lead to Deakin awards or to joint awards of Deakin and a professional body.

Deakin has moved progressively to introduce online facilities and resources over more than a decade, through a combination of anticipating possibilities and responding to demand. Periodic project funding has assisted the process but all parts of the University have participated as part of their mainstream activities. Traditional distance education resources continue to be produced and used, but an interactive element is being added to distance learning that reflects contemporary views on best practice in teaching and learning. Both on- and off-campus students are participants in the online environment.

The problems and issues surrounding this development are not unique to Deakin but reflect particular qualities of this University in its time and place: (a) how to provide facilities that are accessible and easy to use; (b) how to help staff shift from their customary practices to use the online facilities to create rich and engaging learning environments; (c) how to structure support for this transition; (d) how to focus strengths and assure quality to create a sustainable future.

The University has been using the development and implementation of its teaching and learning plan to identify issues, set objectives and implement strategies for resolving them. More than 80 people, staff and students, are participating in the implementation teams and the objectives have expression in the University's annual priorities. These priorities are the subject of reports to the University's Council.

This case study describes features of the University pertinent to the subject,

International Review of Research in Open and Distance Learning 
identifies external and internal factors impacting on development, identifies events that precipitated activity, reviews some of the outcomes, and offers summary observations.

\section{Structure, culture and processes}

\section{Structure}

Deakin is governed by a 21 member University Council comprising ex officio members, appointees and elected staff and students. The Vice-Chancellor reports to Council. The University's Academic Board, with both internal elected and ex officio members, is advisory to Council and, as stated in the Deakin University Act,

may make to the Council any recommendation about the academic affairs of the University and in particular may make to the Council such recommendations as it thinks proper with respect to instruction, studies, examinations and assessments, research, degrees, diplomas and discipline in the University (State of Victoria, 1974).

This governing structure places considerable power in the hands of Council and the Executive and reflects an Australian shift in the 1990s to a more managerial form of university governance (Higher Education Management Review Committee, 1995).

The integrated structure of teaching and support services at Deakin is a legacy of the original university established in 1975. An "open campus" was envisioned wherein all students, whether on campus or off, would use the same high quality learning resources and have opportunities for meaningful interaction with staff and peers (Jevons, 1982). Thus, on-campus students would not only attend classes (primarily of the tutorial variety) but they would also receive the study materials normally provided to distance learners. Off-campus students would receive these traditional distance learning resources and have access to residential schools, itinerant tutors or, later, audio teleconferences. While the open campus model was never applied in all programs of study, and while there was slippage to more traditional classes for on-campus students and heavier reliance on learning resources for off-campus students, the concept remained firmly part of the culture. Importantly, it was extended to the organisation of academic support and administration, with each Division charged to provide equivalent, if not identical, services to all students, whatever their mode of study. This form of organisation has had a certain benefit as the use of online technologies becomes ubiquitous: each faculty and division has a core understanding of flexible provision and an infrastructure that accommodates this.

International Review of Research in Open and Distance Learning 
The multi-campus nature of the University is another important structural feature. There is a need to teach the same courses on different campuses and off campus, and to ensure the same coverage of topics and the same standards across campuses that previously were different institutions. This has encouraged the use of uniform learning resources and the rapid adoption of online communication in the University, for administrative purposes as well as teaching and learning.

Like most universities with a major distance education component, Deakin has always had a central unit responsible for educational design and learning resource development. This unit has had different names and configurations over the years, sometimes a single unit and sometimes split into educational development and learning resource divisions. Nonetheless, it has provided a focus for consistency in the quality and style of learning resources and a site from which to develop, promote and support the use of online technologies. The structural challenge in the shift from traditional distance education to online approaches has been to revise staff responsibilities and change the pattern of work without simply adding new functions.

Deakin Australia is another important structural factor. From the time of its establishment, it has operated in some ways at arm's length from the University. When it offers award courses, they are courses of the University and subject to the standard approval and accreditation processes. Much of its work, however, is in the provision of educational services for its clients. The need to operate flexibly and quickly led to the establishment of its own parallel infrastructure. In the move to the online environment, there are recognised benefits in collaborative development of infrastructure and sharing of expertise, and there is a consequent increase in joint activity.

\section{Culture}

The merger of three institutions, one a university with a research and teaching culture and two colleges, which were vocationally oriented and not funded for research, has required the development of a common culture independent of mode of study. There were also, however, differences in approaches to teaching and learning. Traditionally, the colleges had much more contact time for oncampus students, and staff have been forced to reduce this intensive face-to-face teaching. In addition, the academic staff on the Melbourne campuses faced the new expectation that they would develop learning resources and teach at a distance; Warrnambool, in contrast, located in a region with a low population base, had previously augmented its on-campus enrolments with distance learners. In Geelong, although the different schools of the University varied in the degree to which they enrolled distance students in their principal programs, there was a shared understanding of distance education that placed heavy reliance on the learning resources. References to "tutorials in print" implied that the materials 
did the teaching and the infrastructure of the 1980s did not make provision for easy telephone contact with academic staff or other forms of access to academic advice when students needed it. Though it might have been expected that this would lead to emphasis on the use of online technologies for depositing and distributing learning materials, there has been a strong thrust towards computer communication.

There is a tradition in Australian universities of coordinated curricula with prescribed content in units (equivalent to courses in North American parlance) and common resources, assignments and examinations, however many people may be involved in the teaching. This is consistent with the usual practice in single mode distance teaching universities. In addition, Deakin espoused the course team approach, initiated by the UK Open University, for the development of learning resources. The culture thus supports a collaborative approach to teaching and learning. While what goes on in a classroom at Deakin may not be open to external observation, many elements of teaching are not private or at the discretion of the academic staff member.

Furthermore, as in many single mode distance teaching universities, academic staff develop learning resources as one of their normal responsibilities and the University owns these resources. The University thus far has not seen the debates about intellectual property that have arisen as traditionally campus-based universities move to distance and online education. Another interesting point is that Deakin policy does not encourage staff to develop learning resources for personal profit and sale: academic staff must obtain the permission of the Council to assign commercial textbooks that they have written in their courses.

Finally, the last decade has seen dramatic changes in Australian higher education, driven by government, that are reflected in cultural change. One is a shift from collegial to more managerial forms of governance; another is reduced core government funding and the need to seek resources from other sources; a third is increased attention to measures of performance. Universities are operating more strategically and becoming more market-oriented and customer-focused. This is reflected in Deakin's aim to reach out to more fee-paying and international markets using its distance education expertise and experience in an online environment.

\section{Processes}

Deakin's strategic priorities are set out in the "Strategic Planning Framework 1999 - 2001" (Deakin University, 1999) which was adopted by the University's Council. This is a short document that consists of a vision statement, a set of values, nine strategic priorities and a small number of key performance indicators. Underpinning and aligned to the Strategic Planning Framework are plans covering specific performance areas (e.g., Deakin University, 2000) and 
the strategic plans of faculties and divisions. Council approves annual priorities distilled from the various underpinning plans and receives both qualitative reports on achievement and quantitative reports on strategic and operational performance indicators. In this way, the broad strategic priorities are given substance and a clear line of reporting and accountability is established. To illustrate, the University's current strategic priority for teaching and learning is:

Strengthen teaching and learning, including flexible and lifelong learning, through focused planning for course development and delivery and an increased emphasis on attracting and retaining an outstanding and diverse body of students and staff (Deakin University, 1999).

The two objectives in the teaching and learning plan that are most relevant to this case study are:

Objective 10: Deakin will build upon its reputation in the provision of distance and flexible enrolment and study options to become a global university, respected internationally both for the quality of its educational provision and for innovative application of information technology to teaching.

Objective 11: Deakin will restructure its flexible learning support services to provide support and strategic guidance for its globalisation strategy. (Deakin University, 2000)

In the annual priorities for 2000, several strategies address these objectives; for example:

- Implement the instructional management system with strategies and schedule for deployment and appropriate training;

- Develop a University plan for a systematic and targeted approach to distance and flexible learning; and

- Complete the administrative restructure of teaching and learning support services.

It is important to note the process of widespread consultation in the development and implementation of University plans. For example, the teaching and learning plan was developed over an academic year under the direction of the Deputy Vice-Chancellor. A small working party was responsible for drafting; 
the Academic Board and Executive oversaw the process through their Joint Committee on Teaching and Learning; a consultative draft was circulated for comment throughout the University community in mid-year; and the Academic Board approved the plan before it was submitted to Council. Six teams, comprising approximately 80 individuals drawn from academic and general staff and students, are overseeing the implementation. One of these teams has produced discussion papers and a draft plan for the establishment of a virtual or e-campus.

This consultative process has several benefits: it helps ensure that issues of concern to students and staff throughout the University are identified and addressed; it provides a forum for discussing potential strategies and solutions; and it raises awareness of matters of strategic importance. These are particularly important in a multi-campus university with different prior cultures and practices.

\section{Extra-institutional factors}

\section{Government policy}

The federal government exerts considerable influence over higher education in Australia. This was illustrated in a study of University Autonomy in Twenty Countries by Anderson and Johnson (1998). They concluded that, while the government has limited power (comparable to "Anglo-American" countries) to direct higher education, it is like the mid-range European countries in the degree to which it is perceived to exert influence. Some of its policy directions have had a significant effect on the development of distance and online education.

One example is the encouragement of universities to use information and communication technologies for teaching and learning. Beginning in 1989 and continuing to the mid-1990s, it was a government strategy to use distance education as a wedge to drive technology into the universities. While the reasons for this were not simple or easy to interpret, it is notable that a government report (House of Representatives Standing Committee on Employment, Education and Training, 1989) advocating coordinated encouragement of technological innovation at all levels of education coincided with the selection of seven leading distance teaching universities, their designation as national Distance Education Centres and the establishment of a coordinating body, the National Distance Education Conference, with a government-managed agenda. The strategy was evident, for example, in the allocation of equipment grants from the National Priority Reserve Fund to universities designated as Distance Education Centres, in the funding of a technological innovations program through Open Learning Australia and in commissioned reports (e.g., Deakin University, 1993). A grant of $\$ 2.27$ million to Deakin University for an Information Technology Enhancement Program provided a major impetus for online developments (see below).

International Review of Research in Open and Distance Learning 
A second example is the shift in rules about the charging of student fees. Until the late 1980s, there were no fees in Australian higher education. A Higher Education Contribution Scheme was then introduced in which students had the choice of paying nationally fixed fees at a discount on enrolment or later through their taxes when they were in the workforce. A subsequent series of rule changes have affected the market for distance and online education: postgraduate programs (other than higher degrees by research) were first permitted to attract discretionary fees above the base level and now are no longer subsidised by government. This sort of rule change can dramatically affect enrolment in a period as short as a year.

\section{Online access}

The use of information and communication technologies is dependent on student access to the online environment. A national survey of open learning and distance education students as early as 1993 found that $77 \%$ had access to computers, $58 \%$ had some experience with computer communication and over $80 \%$ thought that electronic mail and computer conferencing would be useful in their courses. Thus, students even at that time were well ahead of the general public in their adoption of communication technology and were well disposed to its introduction. This prompted the University to move ahead in 1995 to expand the use of e-mail for academic communication and support services, to introduce FirstClass computer conferencing facilities and to expand its use of the WWW. Current information supports the view that Deakin now can reasonably expect all students to arrange their own computer access, with the possible need to provide assistance in exceptional cases, and a draft policy to this effect is under consideration. The decision will be influenced by an investigation by the Australian Vice-Chancellors' Committee into the legality of such a requirement.

The other factor in online access is the method of connection. In the early years, Deakin facilitated connection by subscribing to datapac services, negotiating modem access in major centres and providing its own modem bank. These unwieldy solutions were superseded by widespread accessibility of Internet service providers (ISP). From 1998 all students except those studying for higher degrees by research were required to use an ISP to access the University from home. This policy change was readily accepted. Connect time and its associated costs continue to be factors since most homes in Australia do not have high

bandwidth access to the Internet at flat rates. High bandwidth is restricted to certain neighbourhoods in major cities and costs are highly dependent on location and extremely volatile. Deakin has devised strategies to minimise connect time.

International Review of Research in Open and Distance Learning 


\section{Competition}

Competition is a salient feature of the current environment. Particularly noteworthy are the movement of campus-based universities directly into the online marketplace and the establishment of consortia, such as Universitas 21 and the Global University Alliance, the latter for the express purpose of marketing and supporting programs of its members. Deakin Australia was an early and successful provider of educational services for corporations and professions and the University was Joint Australian University of the Year in 1999 on the basis of its educational partnerships. It is essential for the University to ensure that its methods and services continue to be at the forefront and to continually evaluate its partnerships and alliances.

\section{Institutional environmental demands}

In the first half of the 1990s, Deakin focused on consolidating the merged institutions, expanding distance education programs and building entrepreneurial educational services. The current leadership has taken a strategic focus which, for teaching and learning, is aimed at: (a) identifying and promoting high profile and high quality programs, (b) recasting the University's distance education mission to reflect contemporary circumstances and future developments, (c) improving and realigning supporting infrastructure to meet current and future needs, (d) assuring staff capability to operate in the new environment, and (e) ensuring sustainable programs and practices.

The impetus for more comprehensive online developments can be traced to three principal sources. The first is staff. The facilitative strategy of providing central facilities, infrastructure and support has enabled adoption by enthusiasts and the spread of enthusiasm, so that a considerable number of programs now have embedded online elements that are considered essential to learning outcomes. Furthermore, some programs would now lack credibility if students were not developing and using online skills. Academic staff, therefore, are advocates for improved systems and support. The second is the Executive which has recognised that distance education is its best vehicle for expanding its educational market and that effective use of the online environment is essential for this. The third is the University's teaching and learning management plan. It espouses a vision for the student learning experience that emphasises interaction and collaboration as well as the development of skills, such as teamwork and information and technological literacy, which an online environment can assist. The teaching and learning plan has policy status and from 2001 all courses undergoing initial and continuing accreditation will be scrutinised for evidence that the skills are being developed.

Several developments relevant to online education reflect these internal de-

International Review of Research in Open and Distance Learning 
mands:

- A university-wide instructional management system, using TopClass, will be linked to the University's information systems and provide integrated administrative and teaching tools. Full implementation will commence in 2001.

- The University's website is being redesigned and one aim is that it better reflect Deakin's virtual or e-campus; in conjunction with this, new services and facilities are being developed.

- The exponential growth in the use of computer conferencing, for oncampus as well as off-campus students, has resulted in a decision to upgrade the University's FirstClass licence.

- Academic professional development programs, and their associated funding, reflect staff training needs including, in these times of budget constraint, the need to teach efficiently as well as effectively.

- Ongoing assistance in the use of technologies is provided through a combination of a 24-hour help desk and staff in local work areas.

- Learning Services, the central unit that advises on learning environments and develops learning resources has been restructured to reflect the requirements of online teaching and learning.

- Accreditation and quality assurance policies and criteria are being revised and will include explicit consideration of teaching and learning strategies as they relate to specified learning outcomes.

Money is an over-riding institutional concern. Australian public funding for higher education is low and falling, and diversification of funding sources is a relatively new phenomenon. Dramatic changes in teaching and learning have occurred in concert with increased workloads. The challenge for Deakin is to craft a sustainable future at the forefront of practice.

\section{Critical incidents}

\section{Progressive movement online}

Deakin has been characterised by progressive introduction of online technologies over a long period of time. Its first systematic use of online communication began in 1981 in a Graduate Diploma of Computing. From 1987 all students were automatically given free e-mail accounts. The real growth of online communication in programs of study began in 1990, however, after an easy-to-use 
text-based system (known as TEAS), with bulletin board and e-mail capabilities, was developed for a particular course and presented as a model for other programs. With rapid developments in technology and enthusiasm generated by TEAS, a more sophisticated system (Deakin Interchange) was introduced in 1995. Installation, from a set of disks, enabled students to open a desktop environment with web browser, e-mail, computer conferencing and other software now relegated to memory (e.g., FTP and Telnet). Although comparatively awkward to install and use by today's standards, Deakin Interchange marked the beginning of growth in the use of computer conferencing (from 45 users in 1995 to 5,000 in 1997). From 1998 a simpler solution was adopted: students and staff received the Deakin Learning Toolkit, a CD-ROM operating like a web browser with information, software, tutorials on the use of some programs and services, and hot links to University websites. This enables remote and on-campus students and staff to participate in the same online environment. A new Toolkit is issued annually. Using computer conferencing as an indicator, in 1998 there were 7,000 users and in 2000 there are 22,000 users. At last count, 4,719 separate conferences were operating.

In these developments, the University has anticipated as well as responded to demand; in fact, TEAS was developed on the side by interested academic and computing staff without central funding or support. In each iteration, the aim was for an integrated system, easy to install and operate, used by students and staff. Both Interchange and the Toolkit have provided tools that students and staff use in their wider university life, not just in courses. Again using computer conferencing for illustration, there are public conferences for cafeteriastyle conversation and student services staff moderate discussions on aspects of student life.

Another aspect of the progressive movement online is the initiation of major development projects to fashion online environments tailored to the needs of particular programs. In these developments, the online component is integrated into the overall design of the program and either replaces other activities (which may have been paper-based, for example) or adds elements that previously were missing or less adequately provided.

For traditional distance education courses that currently make little use of the online environment, the issue for redevelopment concerns the mix of print and online resources. There is no suggestion that print will disappear, but there are discussions in faculties and in Learning Services about how extensively a systemic online environment should be deployed and how this should affect traditional practices (such as the preparation of extensive study guides). There is opportunity to apply agreed principles because the University provides central support for development and production.

International Review of Research in Open and Distance Learning 


\section{Program rationalisation}

The introduction of online communication technologies on a large scale began around the time of the University's mergers and presented somewhat different conceptual challenges for those accustomed to primarily print-based distance education and those accustomed to intensive face-to-face teaching. Interestingly, the need to develop common teaching programs across the University provided an opportunity not only to develop a common teaching culture but also to introduce online components as a standard feature of redeveloped courses. This was particularly evident in the Bachelor of Commerce which replaced myriad undergraduate business degrees. The coordinators of its development ensured that computer conferencing would be a standard feature for off-campus students, and resources were also provided to develop a number of computer-aided learning programs. The online features of this program have become standard for on-campus students as well.

\section{Government project funding}

The University's efforts to develop the use of information technology for teaching and learning were given a major boost in 1994 by a federal government grant of $\$ 2.27$ million (Holt \& Thompson, 1997). This grant enabled the establishment of a multimedia resource and development centre and enhancement of the University's capacity in several areas: (a) computer-mediated communication, (b) computer-managed learning, (c) digital imaging and storage, and (d) library electronic course updater and reserve.

Beyond the value of tied funds for development, the numerous projects operating under a single management framework with clear accountability provided a strong focus on online development and engaged people throughout the University.

\section{Flexible learning initiatives}

In 1997, the Deputy Vice-Chancellor and the Vice-President (Administration) jointly established a fund to assist faculties to move courses online with the support of the central educational development unit. The aim was to facilitate the mainstream use of low-end, low-cost, high-volume and easily achievable technologies. In mid-year, they rolled together this initiative and a suite of other projects and programs under the heading "flexible learning initiatives". Included were: (a) a research and development program using leading-edge technologies for integrated online teaching and learning, (b) a video conferencing project, (c) the development of the Deakin Learning Toolkit CD-ROM, (d) a review and redesign of learning materials development and production pro- 
cesses, (e) a professional development program to support flexible teaching and learning, and (f) several projects focusing on redesigning aspects of the University's infrastructure.

Most of the projects and programs had reference groups but, in addition, a representative coordinating committee and several subcommittees were established. The effect was to improve planning and accountability, to ensure increased cooperation among faculties and divisions and to improve the perception of communication and consultation.

\section{Plan-driven development}

With the arrival of a new Deputy Vice-Chancellor in 1999 and the adoption of the "Strategic Planning Framework 1999 - 2001," the University's planning became more focused and placed greater emphasis on specifying outcomes and on strategic use of available resources. Implementation of the teaching and learning plan (Deakin University, 2000) involves clearer identification of target student markets and high priority courses as well as articulation of the University's principles and strategies for operating online. Whereas in the past there was a tendency simply to add new programs and facilities, the dominant aim now is to create a sustainable future where high quality is assured.

\section{Intended and unintended consequences}

\section{The learning/teaching system}

In a dual mode university like Deakin, the introduction of online facilities for teaching and learning reduces any justification for treating on-campus and offcampus students separately. The resources and facilities provided in the online environment can enrich the learning experiences of both. Just as Deakin traditionally provided its off-campus study materials to on-campus students, so the online facilities are typically available to everyone.

In online teaching and learning it is necessary to rethink teaching and learning strategies for on-campus as well as off-campus students. Online technologies offer irresistible opportunities to increase and entrench communication and interaction in the learning experiences of off-campus students, thereby improving their quality and scope. The experiences of on-campus students, for whom faceto-face interaction is assumed, though not always assured as class sizes increase, are also enriched by access to online resources and experiences. While the results of evaluations are largely encouraging, much work remains to be done to ensure that these aspirations are fulfilled. In particular, there is some anecdotal 
evidence that some students need to be convinced that interaction that involves group work is of benefit to them. This is part of the work of selling the principles embodied in the teaching and learning plan to students.

Course teams, implemented on the UK Open University model in the 1970s and reaffirmed in 1990, are gaining new relevance in the online environment. With diverse roles to be filled, there are opportunities for academic staff to make contributions that reflect their strengths and interests. In traditional distance education, course team members collaborated in the development and review of topics for fixed, and mainly print-based, learning resources. In the online environment they can extend the collaboration to learning facilitation, managing learning environments and teams, managing the deployment and use of resources, working with clients and collaborators, advising students, managing assessment, and monitoring and evaluation.

\section{Institutional level operational systems}

While Deakin has not had the plethora of local online solutions that characterises some universities, the coordinated flexible learning initiatives and subsequent plan-driven development prepared the way for an institutional instructional management system as the platform for online programs. This is seen as the most effective way of supporting online education across the University. The particular solution being implemented uses TopClass linked to the University's information systems and to FirstClass in order to sustain the accustomed level of sophistication in computer conferencing.

The library and the divisions of the University that provide academic, administrative and technical support have moved dramatically to provide online services and support, and they work much more collaboratively than they did in the past, both among themselves and with the faculties. The Deakin Learning Toolkit, the instructional management system and the University's WWW environment have provided one focus for this collaboration, requiring input from several divisions of the University as well as the faculties. Another example is the collaboration of Learning Services, Information Technology Services and the Library in the establishment of digital repositories and metadata systems.

\section{The course development management system}

The traditional learning services that provided educational design and resource development and production services for distance education have been restructured and new positions have been created. The restructuring has taken place without layoffs although there has been some natural attrition. While there is still considerable production of print-based learning resources, there is increasing emphasis on assisting academic staff to design and use online learning environ-

International Review of Research in Open and Distance Learning 
ments and resources. The restructuring has been a difficult process for some staff who have seen their accustomed jobs disappear or change dramatically and have been required to develop new skills for new responsibilities.

\section{The course delivery management system}

The distinction between course development and course delivery is blurring. In traditional distance education, the development and production of static learning resources was distinct from the learning process. Online environments, in contrast, are dynamic, providing opportunities to add and manipulate resources as well as for interaction. While resources are still developed in advance, they can no longer be seen as doing the teaching; the process becomes the central feature.

\section{Implications and conclusions}

In 2000, one of the teams involved in the implementation of the teaching and learning plan has focused on identification of issues for the renewal of Deakin's distance education. This work informs the implications and conclusions drawn from this case study.

\section{The institution}

For the University, the shift from traditional distance education to the online environment has been prompted by consideration of its place in a wider world than the parochial Australian higher education system. Where does it fit among the newly emerging institutional models? What markets will it aim for and where will they be? Will it be a global university and, if so, what does that mean? Whom will it be competing with and how? What new alliances does it need to form? How can it build on its early and successful start with its corporate and professional programs? What information should it draw on to inform its decisions?

Alongside these questions about Deakin's future place in the expanded world is the issue of how it will represent its online environment. It already has an extensive one but until recently it has not thought of it as a virtual or e-campus. This concept is providing a way of visualising an integrated presence comprised of what to now has been thought of as a collection of systems, facilities and activities. 


\section{The administration}

For the administration, it has been useful to have the central divisions providing on- and off-campus services under one budget line. Though the challenges of shifting from traditional practices cannot be underestimated, there is a culture of providing off-campus services that translates nicely to providing online services. The online environment, with its requirement for integrated systems, has dramatically increased the collaboration among divisions, notably the library, academic administration, student services, information technology and learning services. What were once discrete operations are brought together.

In some areas, especially in the Learning Services division which is traditionally responsible for developing and producing distance education resources, the work of staff is being transformed. In traditional distance education, the emphasis was on product: the learning resources. In the online environment, the emphasis shifts to include not only planning for courses but consideration of what occurs during learning. Learning resources may even be dynamically created during the process. Much of the assistance to academic staff must be to help them facilitate learning in the online environment. All of the positions have been reviewed, and some have been dropped and replaced with new descriptions. Most new positions are being filled with existing staff and the transition from old to new work practices is underway. This is a daunting task that has been stressful and taken considerable time.

The shift online also raises resourcing issues. Many of the major advances at Deakin have been started with internally or externally funded projects. In reality, however, the University's online environment needs to be part of its mainstream operations and funded within the normal budget process. Equipment and corporate systems are funded annually from the central budget. Budget centres need to ensure that their priorities encompass online developments and that they have staff who can work to these priorities. The central, as well as local, staff development budgets need to fund programs for both academic and general staff to assist them in using the online environment.

\section{Academic staff}

Staffing policies and models need to be appropriate to the diverse requirements of teaching and learning environments with online components. The currently circulating discussion paper asserts that the University needs to ensure that its best scholars and teachers have central roles in planning and developing teaching and learning programs and in the process of managing and moderating learning environments. Furthermore, it needs course team models that permit division of labour and recognise contributions based on individuals' specialist skills. The introduction of online facilities into teaching and learning environments requires the filling of multiple roles (e.g., course planning and design, learning facilita-

International Review of Research in Open and Distance Learning 
tion, managing learning environments and teams, managing the deployment and use of resources, working with clients and collaborators, advising students, managing assessment and monitoring and evaluation). These developments are consistent with Deakin's structure, with its multiple campuses and coordinated teaching of units and courses, and its approaches to the use of learning resources. It is neither efficient nor supportive of effective learning to assume that all the roles are filled by a single entity or individual, the teacher.

In addition, the full development of the e-campus will create an e-campus community that may benefit from and be strengthened by staff, as well as students, who are geographically dispersed. These could include scholars and practitioners who undertake part-time appointments to contribute their special expertise to Deakin courses (comparable to the growing number of international scholars with concurrent appointments in institutions in different countries) and qualified academics who play an ongoing role in facilitating learning, perhaps contributing international perspectives or providing interpretations and support in different localities. Facilitative policies should strengthen the University's learning community and enhance its reputation as a leading institution.

Staff working in the e-campus need appropriate training in online technologies and pedagogies and the integration of these technologies with other modes and resources in teaching and learning environments, and access to advice on teaching and learning strategies when they need it. The use of online technologies in teaching and learning environments is relatively new for many staff. Furthermore, the technologies and facilities are developing and changing rapidly, providing new opportunities and challenges. Continuing professional development is essential to support teachers' creative approaches to teaching and learning and their ability make effective use of opportunities to enhance administration, the use of resources and communication.

Staff need to feel encouraged to participate in online teaching and learning and to integrate it with other modes and resources, and to be recognised and rewarded for their positive contributions to effective teaching and learning. The University needs to foster a culture where staff feel that they are creating and enhancing their own futures by developing their skills, participating in online teaching and learning and contributing to Deakin's general expertise. A representative team of staff and students has advocated that specific attention be directed to: appointment, tenure and promotion criteria; the principles and processes for allocating workload; and strategies for recognising and rewarding contributions to online learning.

\section{Students}

Deakin students have welcomed the online facilities and services provided by the University. Increasing numbers of programs make use of educational tech- 
nologies in their core activities and academic support areas have developed programs, including discussion groups that use computer conferencing, and that mirror or extend on-campus services. There is also a lively social life that is conducted via computer conferencing. It is important to note that it is not only off-campus students who spend time in this environment. While it is rapidly becoming an essential aspect of student life for off-campus students, reducing their sense of isolation and giving them opportunities for collaborative learning that they lacked in the past, the online environment is one in which on-campus and off-campus students mix. There is clear evidence from public computer conferences of such interaction; what is needed now is effort to integrate these students in learning environments. As the e-campus concept is developed and given a more coherent form, it may help generate a sense of identification and engagement that aids motivation. Whether it leads to better learning will depend on the collective ability of the members of the University to use online facilities to create rich and stimulating learning environments.

International Review of Research in Open and Distance Learning 


\section{References}

Anderson, D., \& Johnson, R. (1998). University autonomy in twenty countries. Higher Education Division Evaluations and Investigations Program. Canberra: Australian Government Publishing Service. Retrieved December 13, 2000: [http://www.detya.gov.au/highered/eippubs/eip98-3/execsum. $\mathrm{htm}]$

Deakin University. (1999). Strategic planning framework 1999 - 2001. Retrieved December 13, 2000: [http://www.deakin.edu.au/vice_chancellor/ $\mathrm{vc/strategic.html]}$

Deakin University. (2000). The competitive edge: Deakin University teaching and learning management plan 2000 - 2002. Retrieved December 13, 2000: [http://dugs.deakin.edu.au/Deakin+SOP.nsf/6fae0c2dde672347ca25677b0048c7a3/ f71a5fd36dcc9facca2568b20001de41?0penDocument]

Deakin University in collaboration with Strategic Technology Management Pty Ltd. (1993). Electronic facilities network to enhance tertiary open learning facilities. Higher Education Division Occasional Papers Series. Canberra: Australian Government Publishing Service.

Higher Education Management Review Committee (1995). Higher Education Management Review (the Hoare Report). Canberra: Australian Government Publishing Service. Retrieved December 13, 2000: [http://www. detya.gov.au/highered/otherpub/hoare/hoareidx.htm]

Holt, D. L., \& Thompson, D. (1997). Information Technology Enhancement Project: Final report. Geelong: Deakin University.

House of Representatives Standing Committee on Employment, Education and Training (1989). An apple for the teacher? Choice and technology in learning. Canberra: Australian Government Publishing Service.

Jevons, F. R. (1982). How different is the distance student? In J. S. Daniel, M. A. Stroud, M. A. \& J. R. Thompson (Eds.), Learning at a distance: A world perspective (pp. 126-128). Edmonton, AB: Athabasca University.

State of Victoria (1974). Deakin University Act. Retrieved January 9, 2000: [http://www.austlii.edu.au/au/legis/vic/consol_act/dua1974211/s27. html]. 


\section{Citation Format}

Calvert, Jocelyn (January 2001) Deakin University: Going Online At A Dual Mode

University. International Review of Research in Open and Distance Learning: 1, 2.

http://www.icaap.org/iuicode?149.1.2.8 